\title{
Solute Concentration in the Kidney-
}

\section{A Model of the Renal Medulla and Its Limit Cases*}

\author{
JOHN A. JACQUEZ, DAVID FOSTER \\ AND
}

\section{EUGENE DANIELS}

The Department of Physiologv, The Medical School, The University of Michigan, Ann Arbor, Michigan 48109

\begin{abstract}
We develop a general model of the renal medulla that is similar in geometry to the models reported by others. Two solutes are assumed to be present, one to play the role of salt and the other that of urea and similarly handled compounds. The equations from irreversible thermodynamics are used to describe simultaneous solvent and solute flow across tubular membranes and a salt pump, saturable in the cis concentration and inhibited by trans concentrations is included in the AHL. We examine the input limit cases of the model, i.e., those for zero and infinite inflows in vasa rectae, Henle loop and collecting ducts. High inflow to vasa rectac washes out the gradients. For inflow to DHL there is an optimal value for building up the concentration gradients: for zero inflow, no concentration gradients are developed and as inflow increases above the optimal value, the concentration gradients decrease and all concentrations in DHL, AHL and interstitium tend towards those in the inflow to DHL. A central core model, the limit case for zero inflow in vasa rectae, is then described.
\end{abstract}

\section{KEY WORDS}

Kidney, medulla, concentration gradient, model, limit case, central core.

\section{INTRODUCTION}

The countercurrent multiplier theory of the operation of the renal medulla is of ten attributed to Kuhn and Ryffel [1]. However, this theory was stated more explicitly by Hargitay and Kuhn [2] who proposed a model

*This work was supported in part by grants AM 16635 and GM 00110 from the National Institutes of Health, DHEW.

MATHEMATICAL BIOSCIENCES 32, 307-335 (1976)

(c) American Elsevier Publishing Company, Inc., 1976 
for the operation of the system utilizing hydrostatic pressure as the driving force although they acknowledged that the known pressure differences in the kidney were too small to account for the total force required. Now, however, the evidence is overwhelming in favor of the driving force being the active extrusion of salt from the ascending limb of Henle, although there is disagreement as to whether the ion being pumped is sodium or chloride, and whether or not there is pump activity in the thin portion of that limb [3-9].

The countercurrent hypothesis states that the loops of Henle, acting as a countercurrent multiplier system, establish an osmotic gradient along the renal pyramids with the tips of the pyramids having a higher osmotic pressure than the bases. This theory was supported by the experimental findings of Wirz, Hargitay, and Kuhn [3] who, from their measurements on the melting points of slices of the medulla, reported that the osmolality of the medulla increased from the corticomedullary border to the tips of the papillae. They also reported that all structures at any one level have the same osmolality, a fact we now know to be incorrect since the fluid leaving the ascending limb of Henle is hypotonic. The micropuncture work of Gottschalk and coworkers [10] showed that when the hamster, the kangaroo rat, and the Psammomys were in an antidiuretic state, the fluid in the loops of Henle and the blood in the vasa rectae near the tips of the papillae had the same osmolality as the fluid in the collecting ducts at that level, and that these fluids were hyperosmotic. These findings have established the countercurrent hypothesis as a viable theory, and since the early 1960's all of the experimental evidence has been consistent with its general features.

As the evidence in support of the countercurrent mechanism has increased, there has been a concomitant increase in the effort to develop more detailed models of the medulla. The early attempts were hampered by the fact that although the geometry of the medulla was fairly well worked out, the bulk of the evidence supporting the countercurrent hypothesis provided little insight into the details of how the various tubular segments functioned. In the early part of this decade, however, there were two significant developments which have had a major impact on the development of models of the medulla.

The first of these was that techniques to measure the electrical and permeability properties of isolated tubular segments were perfected [11]. The in vitro data so obtained gave, for the first time, direct evidence as to how these segments probably functioned in vivo thereby allowing refinements to be made to the countercurrent hypothesis.

The second of these deals with the vasa rectae. If the assumption is made that the vasa rectae are highly permeable to nonprotein solutes and in equilibrium with the medullary interstitium at any given level in the 
medulla, then it is possible to merge them with the interstitium to form a larger fluid filled space. The advantage to using this assumption is that it simplifies the geometry of the medulla considerably while leaving the concentrating mechanism intact. This assumption was first used by Kokko and Rector [6] and Stephenson [12]. Kokko and Rector formulated a model of the inner medulla to examine the countercurrent multiplication system without active transport and used this assumption to simplify the calculations. Subsequent computer simulations based upon this model were carried out by Stewart et al. $[13,14]$ although it should be pointed out that they used an ad hoc assumption on water movement to force volume balance. Stephenson used it because under the assumptions of the central core model the functional role of the vasculature is retained but the model is greatly simplified. Initially, he analyzed the general properties of the central core model and calculated the energy requirements for the concentration of urine $[12,15,16]$. Later, he reported some concentration profiles in the medulla in a normalized form [17].

In this paper, we will derive the equations describing two concentrating engines, the geometry and structure of which are motivated by our knowledge of the structure and function of the medulla. The first, called the full model of the medulla, includes provisions for all of the tubular segments which are present in this region, specifically the two limbs of Henle, the two limbs of the vasa rectae and the associated capillary plexus, and the collecting duct. The geometry of this model represents a first approximation to what we know about the anatomy and tubular function in the medulla. Even so, it leads to tremendous difficulties. Indeed, from the mathematical point of vicw it is a difficult two point boundary value problem, and from the physiological point of view, some of the input values and parameters are yet unknown.

If we examine the full model closely we are led to the conclusion that the source of most of the mathematical problems lies with the inclusion of the vasa rectae in the model. Thus we are led in a natural way to seek circumstances under which the vasa rectae might be disregarded. Here the second significant development on the modeling of medullary function comes into play, and at this point we introduce the second model, namely the central core model. We point out that this version of the central core model is the same in general though differing in details from that given by Stephenson [12].

In the next paper, we will use the central core model for our simulations. The question arises why we did not start with it and proceed directly to the simulations. The answer is twofold. One is that we wanted to spell out very carefully the mathematical and physiological consequences in passing from what we know of the medulla to the central core model. Indeed the 
implications as to medullary function which we may deduce from the simulations can only be understood if one understands the basic assumptions of the central core model. The other reason is that the necessity of having to pass from the full model to the central core model points out the fact that much of the experimental data needed to solve the equations of the full model are missing and the mathematics is difficult. It is our hope that these deficiencies will stimulate interest in both directions.

\section{THE FULL MODEL OF THE MEDULLA}

The full model of the medulla which we give in this section is designed in accord with the general evidence for the countercurrent mechanism discussed in the introduction. Therefore, it should be regarded as a model of a countercurrent concentrating engine, and the implications of the model with respect to the medulla itself must be tempered by the underlying assumptions. These assumptions can best be explained in terms of the schematic in Fig. 1. Geometrically we note that this schematic is similar to that used by a number of other authors in modeling renal medullary function.

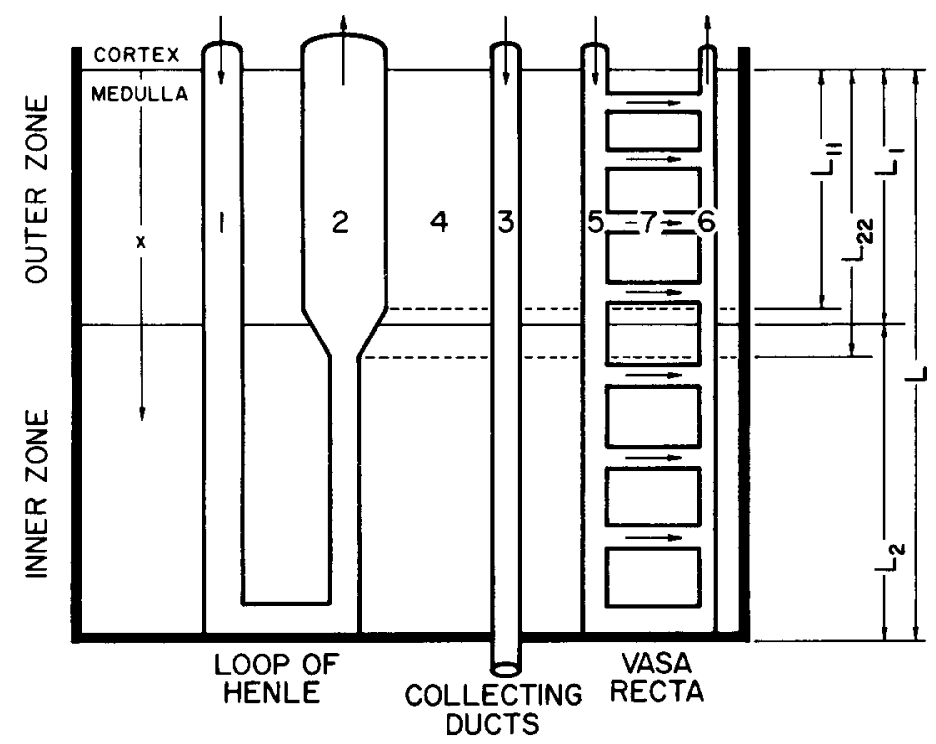

FIG. I. Schematic diagram of model of renal medulla. 1-descending limb of Henle; 2-ascending limb of Henle; 3-collecting ducts; 4 -interstitium; 5 -descending vasa rectae; 6-ascending vasa rectae; 7 -capillary nets connecting descending and ascending vasa rectae. 
GEOMETRY

Tubes 1 and 2 represent the descending (DHL) and ascending (AHL) loops of Henle, respectively. Notice that we have not included the end of the proximal tubule which penetrates into the medulla as it empties into the top of the descending limb. Tube 3 represents the collecting duct (CD). No provision has been made to allow for the highly branched nature of this tube, a feature of the model which we will discuss later. Since the interstitium itself can be regarded as a tube in which all of the other tubes lie, we have labeled it as tube 4. The descending (DVR) and ascending (AVR) vasa rectae are represented by tubes 5 and 6 ; tubes 7 represent the capillary meshwork connecting the two.

The transition between the outer and inner medulla occurs at the junction of the thin AHL with the thick. We have diagrammed this as a linear transition beginning at $L_{11}$ and ending at $L_{22}$. The reason for this is that even though the thick limbs are the same length to within a few percent, the transitions are not abrupt. We would like to point out that this linear transition has an important mathematical consequence. If this transition were abrupt, then there could be discontinuities in certain parameters used in the equations at this point resulting in difficulties in the numerical solutions. For example, urea permeability in the thin AHL is quite high, whereas it is virtually zero in the thick part. With an abrupt transition, the differential equations describing urea movement across the tubular walls would have a discontinuity at this point resulting in oscillations in the numerical solutions. To alleviate this problem, all changes in parameter values between the inner and outer zones have been accomplished by inserting a linear gradient across the transition from $L_{11}$ to $L_{22}$.

\section{LOOPS OF HENLE}

The total amount of material which can exchange across the walls of the DHL and AHL at any given level in the medulla depends in part upon the total surface area per unit length and the total flow rate in the respective tubules at that level. At the corticomedullary border, the total flow into the DHL is determined by the total number of deep nephrons, the deep nephron glomerular filtration rate (GFR), and the percentage of water which is reabsorbed along the proximal convoluted tubule. The total surface area of the AHL and DHL at this point is determined by the total number of deep nephrons together with their respective radii. From species to species, there is a difference not only in the percentage of nephrons that are long looped, but in the number of these nephrons that actually extend to the tips of the papillae. This implies that in any cross section of the medulla the number of tubules can decrease as one goes from the corticomedullary border to the papillae. The result of this is a decrease both in surface area per unit length and in flow rate at deeper levels of the medulla. 


\section{COLLECTING DUCTS}

As indicated in Fig. 1, we regard the collecting ducts as tubes passing through the interstitium, and have assumed a constant surface area per unit length throughout the medulla. Thus we neglect the highly branched nature of these tubes and the fact that the confluence of these structures probably leads to a situation where the flow velocity stays relatively constant along the lengths of the ducts. Because of the complicated geometry of these tubes, it is difficult to estimate the changes in total surface area per unit length since the total number of collecting ducts decreases as one approaches the papillae whereas their radii increase. In our initial model we assumed that all loops have the same length and have constant surface area per unit length. However, in programming the central core model, provision for a changing surface area per unit length as a function of distance was incorporated in the program.

\section{VASA RECTA}

The vasa rectae descend as parallel bundles from the corticomedullary border to form the capillary plexuses at different levels in the medulla [14]. We have lumped these plexuses into a series of tubes cross-connecting the DVR with the AVR. Since the vasa rectae do not enter into the computational model, we will not enumerate the difficulties these simplifications present except to point out that the flow in the cross-connecting tubes is perpendicular to the DVR and AVR (see Fig. 2).

\section{INTERSTITIUM}

The interstitium is assumed to be well-mixed at any one level $x$ from the corticomedullary border. As indicated by the schematic, the tubules interact indirectly via solute and solvent exchange with the interstitium. This ne-

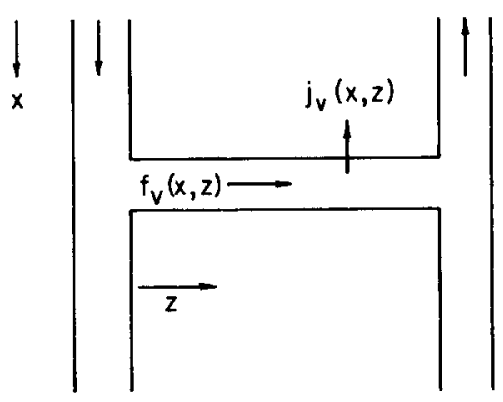

FIG. 2. Schematic diagram showing notation for capillary bed connecting DVR and AVR. 
glects the anatomic evidence [18] which suggests that the tubules are not randomly distributed, and that there may be some direct exchange between tubules such as the DHL and AVR.

\section{TUBULAR FLUIDS}

The fluid in each tube is assumed to contain two solutes, one to play the role of salt and the other urea. In addition, the vasa rectae and their associated capillary plexuses are assumed to contain another solute to play the role of the plasma proteins. No attempt has been made to deal with the ions separately so it is immaterial to the model whether it is sodium or chloride which is actually transported. What is included is the effect of the net movement of salt and the resulting osmotic effect.

\section{PHYSICAL PROCESSES TO BE MODELED}

The basic relations required to describe the processes in each tube are: (1) equations of conservation for solutes and solvent, (2) equations of motion that give the flow rates as functions of the pressure gradients and tube geometry, and (3) equations of state to describe the dependence of the tube diameter on pressure differences across the walls of the tubes. Since we treat fluids as incompressible, we do not require the equations of state for the fluids. Moreover, from the work which has been done on perfused isolated tubules [15] we are led to believe that the tubes are of relatively constant diameter over their length. Thus we treat them as rigid tubes thereby eliminating the equations of state for tube diameters. Furthermore, we believe that the pressure gradient and pressure filtration effects are small for all tubules except the vasa rectae which means that the equations of motion must be included only for the vasa rectae and their capillary networks. However, one must then make some assumptions about the pressure in the interstitium in order to obtain the pressure differences across the walls of the tubules 5, 6 and 7 . Our conclusion, therefore, is that a reasonable first model of the countercurrent concentrating engine as it might apply to the medulla must include the conservation equations for all solutes and solvents for all tubes, and the equations of motion for at least tubes 5,6 and 7 .

\section{SYMBOLS AND NOTATION}

In Table 1, we present a list of symbols together with their respective units which we will use. Except where it is essential for clarity, the independent variable $x$ will not be exhibited. The tube numberings refer to those given in Fig. 1. Thus, the concentration of the $k^{\text {th }}$ solute in tube 5 at a distance $x$ from the corticomedullary border is $c_{5 k}(x)$ which we will write $c_{s k}$. A schematic showing the notation for the capillary bed at a depth $x$ is given in Fig. 2. 
TABLE 1

List of Symbols Used

\begin{tabular}{|c|c|c|}
\hline Symbol & Dimension & Meaning \\
\hline$L$ & $\mathrm{~cm}$ & Total width of the medulla \\
\hline$L_{1}$ & $\mathrm{~cm}$ & Total width of the outer medulla \\
\hline$L_{2}$ & $\mathrm{~cm}$ & Total width of the inner medulla \\
\hline$L_{11}$ & $\mathrm{~cm}$ & $\begin{array}{l}\text { Beginning of linear transition from } \\
\text { outer to inner medulla }\end{array}$ \\
\hline$L_{22}$ & $\mathrm{~cm}$ & $\begin{array}{l}\text { End of the linear transition from the } \\
\text { outer to inner medulla }\end{array}$ \\
\hline$L_{c}$ & $\mathrm{~cm}$ & $\begin{array}{l}\text { Mean length of capillary bed between } \\
\text { vasa rectae }\end{array}$ \\
\hline$x$ & $\mathrm{~cm}$ & $\begin{array}{l}\text { Independent variable distance into } \\
\text { medulla from corticomedullary } \\
\text { border }\end{array}$ \\
\hline$k$ & - & Solutes: $k=1$ is salt; $k=2$ is urea \\
\hline$S_{i}$ & $\mathrm{~cm}^{2} / \mathrm{cm}$ & $\begin{array}{l}\text { Surface area per unit length of tubc } i \text {, } \\
i=1,2,3,5,6\end{array}$ \\
\hline$S_{c}(x)$ & $\mathrm{cm}^{2} / \mathrm{cm}$ & $\begin{array}{l}\text { Surface area per unit length of } \\
\text { capillary bed at depth } x\end{array}$ \\
\hline$F_{i v}$ & $\mathrm{~cm}^{3} / \mathrm{min}$ & Volume flow rate in tube $i$ \\
\hline$F_{i k}$ & mmoles/min & Flow rate of solute $k$ in tube $i$ \\
\hline$c_{i k}$ & $\mathrm{mmole} / \mathrm{cm}^{3}$ & Concentration of $k^{\text {th }}$ solute in tube $i$ \\
\hline$J_{i v}$ & $\mathrm{~cm}^{3} / \mathrm{cm}^{2} \cdot \min$ & $\begin{array}{l}\text { Volume flux across wall of tube } i \text {, } \\
\text { positive outwards }\end{array}$ \\
\hline$J_{i k}$ & $\mathrm{mmole} / \mathrm{cm}^{2} \cdot \min$ & Flux of solute $k$ across tube $i$ \\
\hline$z$ & $\mathrm{~cm}$ & $\begin{array}{l}\text { Independent variable-distance down } \\
\text { capillary bed }\end{array}$ \\
\hline$f_{v}(x, z)$ & $\mathrm{cm}^{3} / \mathrm{cm}^{2} \cdot \min$ & $\begin{array}{l}\text { Density of volume flow in capillaries } \\
\text { at depth } x \text { at a distance } z \text { down the } \\
\text { bed }\end{array}$ \\
\hline$f_{k}(x, z)$ & $\mathrm{mmole} / \mathrm{min}$ & $\begin{array}{l}\text { Density of flow of solute } k \text { at the } \\
\text { same point }\end{array}$ \\
\hline$j_{v}(x, z)$ & $\mathrm{cm}^{3} / \mathrm{cm}^{2} \cdot \min$ & $\begin{array}{l}\text { Density of volume flux across } \\
\text { capillary bed at the same point }\end{array}$ \\
\hline$j_{k}(x, z)$ & $\mathrm{mmole} / \mathrm{cm}^{2} \cdot \min$ & $\begin{array}{l}\text { Density of flux of solute across } \\
\text { capillary bed at the same point }\end{array}$ \\
\hline$L_{\rho i}$ & $\mathrm{~cm}^{3} /$ dyne $\cdot \min$ & $\begin{array}{l}\text { Filtration coefficient for the wall of } \\
\text { tube } i\end{array}$ \\
\hline$\sigma_{i k}$ & - & $\begin{array}{l}\text { Reflection coefficient of solute } k \text { for } \\
\text { tube } i\end{array}$ \\
\hline$\omega_{i k}$ & $\mathrm{mmole} /$ dyne $\cdot \min$ & $\begin{array}{l}\text { Permeability coefficient of solute } k \\
\text { across the wall of tube } i\end{array}$ \\
\hline
\end{tabular}


TABLE I (cont'd)

\begin{tabular}{|c|c|c|}
\hline Symbol & Dimension & Meaning \\
\hline$\Delta P_{i}$ & dyne $/ \mathrm{cm}^{2}$ & $\begin{array}{l}\text { Hydrostatic pressure difference across } \\
\text { the wall of tube } i, P_{4}-P_{i}\end{array}$ \\
\hline$\Delta \pi_{i}$ & dyne $/ \mathrm{cm}^{2}$ & $\begin{array}{l}\text { Osmotic pressure difference across } \\
\text { the wall of tube } i \text { due to impermeable } \\
\text { solutes, } \pi_{4}-\pi_{i}\end{array}$ \\
\hline$T_{i k}$ & - & $\begin{array}{l}\text { Function describing active transport } \\
\text { for solute } k \text { across the wall of tube } i\end{array}$ \\
\hline$b_{i}(x)$ & $\mathrm{cm}^{3} / \mathrm{cm}^{2} \cdot \min$ & $\begin{array}{l}\text { Bulk flow into the capillaries from the } \\
\text { DVR to the AVR; } b_{i}(x)=j_{v}(x, 0)\end{array}$ \\
\hline $\left.\begin{array}{l}c_{50}(x) \\
c_{60}(x)\end{array}\right\}$ & $\mathrm{mmole} / \mathrm{cm}^{3}$ & $\begin{array}{l}\text { Protein concentration in the vasa } \\
\text { rectae at depth } x\end{array}$ \\
\hline$c_{70}(x, z)$ & mmole $/ \mathrm{cm}^{3}$ & $\begin{array}{l}\text { Protein concentration in the cap- } \\
\text { illaries at depth } x \text { and at distances } z \\
\text { along the capillaries }\end{array}$ \\
\hline$c_{c k}(x, z)$ & mmole $/ \mathrm{cm}^{3}$ & $\begin{array}{l}\text { Concentration of solute } k \text { in } \\
\text { capillaries at depth } x \text { in the medulla } \\
\text { and at distance } z \text { along the capillary } \\
\text { connecting DVR and AVR }\end{array}$ \\
\hline
\end{tabular}

\section{THE EQUATIONS FOR THE FULL MODEL}

\section{THE CONSERVATION EQUATIONS}

The conservation equations for all tubules but the interstitium can be written:

$$
\begin{aligned}
& \frac{d F_{i v}}{d x}=-S_{i} J_{i v}, \\
& \frac{d F_{i k}}{d x}=-S_{i} J_{i k} .
\end{aligned}
$$

The axial flow of solute $k$ is

$$
F_{i k}=F_{i v} c_{i k}-A_{i} D_{k} \frac{d c_{i k}}{d x}
$$

where the first term in the equation is the bulk flow contribution and the second is the contribution of axial diffusion. Here $A_{i}$ is the cross-sectional area of tube $i$ and $D_{k}$ is the diffusion coefficient of solute $k$. For the renal medulla, we believe that the axial diffusion term is small in comparison with the bulk flow term, so we neglect it in what follows. Mathematically, we are seeking the zero-th order solution of a singular perturbation problem. 
THE EQUATIONS FOR WATER AND SOLUTE MOVEMENT

In Eqs. (1) and (2), $J_{i n}$ is the total flux of water across tube $i$ and $J_{i k}$ is the total flux of the solute $k$ across tube $i$. The equations describing these should include expressions accounting for each mechanism by which such movement can occur. These include filtration and diffusion across the walls, active transport where applicable, and, in the vasa rectae, bulk flow out into the capillaries. For filtration and diffusion across the tubular walls, we will use the equations for simultaneous volume and solute flow from irreversible thermodynamics [20]. Thus

$$
J_{i v}=-L_{p i}\left(\Delta P_{i}-\Delta \pi_{i}\right)+L_{p i} R T \sum_{k} \sigma_{i k}\left(c_{4 k}-c_{i k}\right)+b_{i}
$$

and

$$
J_{i k}=\left(1-\sigma_{i k}\right) \frac{\left(c_{4 k}+c_{i k}\right)}{2} J_{i v}-\omega_{i k} R T\left(c_{4 k}-c_{i k}\right)+T_{i k}+b_{i} c_{i k}
$$

It follows from the discussion in the previous section that $b_{i}$ is zero except for tubes 5 and 6 , and that $\Delta P_{i}$ is zero except for tubes 5,6 and 7. Note that we have used the arithmetic mean concentration in Eq. (5) instead of $\left(c_{i k}-c_{4 k}\right) / \ln \left(c_{i k} / c_{4 k}\right)$ [20]. This is a good approximation so long as the concentration difference between interstitium and tubule is not large.

\section{THE PUMP TERM}

As we stated earlier, we will neglect the ionic nature of the salt and assume a solute is transported that gives the osmotic effect of the ion that is actually transported, i.e., it does not matter for this model whether it is sodium or chloride which is pumped.

The equation for the pump term is:

$$
T_{i 1}=\frac{C_{i} c_{i 1}}{A_{i}+c_{i 1}+B_{i} c_{41}}
$$

The arguments for this form of the transport function have been given in [21]. Notice that this expression is saturating in the cis concentration $c_{i 1}$, and that the flux is inhibited by increasing trans concentration $c_{41}$. Notice also that this expression differs from that used by Stephenson [17] because of the presence of $B_{i} c_{41}$.

In our model we assume that salt is the only transported solute. This neglects the possibility of urea transport in the collecting duct, a possibility which has been mentioned by Schmidt-Nielsen [22]. 


\section{INTERSTITIUM}

For the interstitium, we can write the conservation equations for volume flow and solute flux as

$$
F_{4 v}(x)=F_{3 v}(L)-\sum_{j \neq 4} F_{j v}(x)
$$

and

$$
F_{4 v}(x) c_{4 k}(x)=F_{3 v}(L) c_{3 k}(L)-\sum_{j \neq 4} F_{j v}(x) c_{j k}(x)
$$

Notice that $F_{3 v}(L)$ is the volume flow rate leaving the collecting ducts, which we take as the urine flow rate.

\section{VASA RECTAE}

The vasa rectae are the only tubules for which the $b_{i}$ are nonzero. By definition, we have

$$
\begin{aligned}
& b_{5}(x)=f_{v}(x, 0), \\
& b_{6}(x)=-f_{v}\left(x, L_{c}\right) .
\end{aligned}
$$

For these tubules we also require the equations of motion. In the case of streamline flow in tubes where exchange is occurring across the tubular walls, the velocity profiles are no longer parabolic [23-25]. The volume flow rate, however, is still proportional to the pressure gradient even though the coefficient is no longer the same as in Poiseuille's equation. Thus, if $K_{1}$ is the constant of proportionality,

$$
F_{5 v}--K_{1} \frac{d P_{5}}{d x}
$$

and

$$
F_{6 v}=-K_{1} \frac{d P_{6}}{d x}
$$

Flow in the vasa rectae is further complicated by the presence of proteins which are responsible for the colloid osmotic pressure. As a result, we must include the conservation equations for proteins. Assuming these proteins do not cross the walls of the vasa rectae but have free access to the capillary 
beds, we can write the equations

$$
\begin{aligned}
& c_{50}(0) F_{5 v}(0)=c_{50}(x) F_{5 v}(x)+S_{5} \int_{0}^{x} c_{50}(\xi) f_{v}(\xi, 0) d \xi, \\
& c_{60}(0) F_{6 v}(0)=c_{60}(x) F_{6 v}(x)+S_{6} \int_{0}^{x} c_{60}(\xi) f_{v}\left(\xi, L_{c}\right) d \xi .
\end{aligned}
$$

Finally, in the capillary bed, equations similar to those for the DVR and AVR can be written. Since the arguments are essentially the same, we simply exhibit these equations.

$$
\begin{aligned}
\frac{d f_{v}(x, z)}{d z} & =-S_{c} j_{v}(x, z), \\
\frac{d f_{k}(x, z)}{d z} & =-S_{c} j_{k}(x, z), \\
j_{v}(x, z) & =-L_{p c}\left[\Delta P_{c}-\Delta \pi_{c}\right]+L_{p c} R T \sum_{k} \sigma_{c k}\left(c_{4 k}-c_{c k}\right), \\
j_{k}(x, z) & =\left(1-\sigma_{c k}\right)\left(\frac{c_{4 k}+c_{c k}}{2}\right) j_{v}-\omega_{c k} R T\left(c_{4 k}-c_{c k}\right), \\
f_{v}(x, z) & =-K_{c} \frac{d P_{c}}{d z}, \\
c_{50}(x) f_{v}(x, 0) & =c_{70}(x, z) f_{v}(x, z) .
\end{aligned}
$$

\section{BOUNDARY CONDITIONS}

The equations which we wish to solve are Eqs. (1) for tubes 1 through 6 and (2) for the two solutes for tubes 1 through 6 . This gives us 18 equations. In addition, Eqs. (11) and (12) give us two more. Thus, to solve these equations, we need 20 boundary values. These values consist of known values such as concentrations and initial flow rates in tubes 1,3 , and 5 , and matching conditions at $x=L$. The boundary conditions which are obvious from physical considerations are listed in Table 2. This list contains only 18 values, so we must find two more. These can be demonstrated for the lower boundary $x=L$, but we will defer consideration of this until we have obtained the central core approximation.

There is another problem with respect to the boundary conditions, and this is that Eqs. (15), (16), and (19) must be solved at each level $x$. This then makes the problem an accessory two point boundary value problem, and demonstrates clearly the theoretical difficulties presented by the inclusion of the vasa rectae in the computational model. 
TABLE 2

Boundary Conditions for Full Model

\begin{tabular}{ll}
\hline Known values & Matching conditions \\
\hline$F_{1 v}(0)^{*}$ & $F_{1 v}(L)=-F_{2 v}(L)^{*}$ \\
$F_{3 v}(0)^{*}$ & $F_{5 v}(L)=-F_{6 v}(L)$ \\
$F_{5 v}(0)$ & $\left.c_{1 k}(L)=c_{2 k}(L)^{*}\right\} \quad k=1,2$ \\
$c_{1 k}(0)^{*}$ \\
$\left.c_{3 k}(0)^{*}\right\} k=1,2$ & $c_{5 k}(L)=c_{6 k}(L)$ \\
$c_{5 k}(0)$ & $P_{5}(L)=P_{6}(L)$ \\
$P_{5}(0)$ & \\
$F_{4 v}(L)=0^{*}$ & \\
\hline
\end{tabular}

*The boundary values marked with an asterisk $\left({ }^{*}\right)$ are those remaining in the central core model.

\section{THE LIMIT CASES FOR THE FULL MODEL}

In order to solve the equations which describe the model, we must have in addition to the boundary conditions numerical values for the parameters and inputs listed in Table 2. From a mathematical point of view, each of these parameters and inputs has a maximal interval containing all of the possible values it can assume. For example, the reflection coefficients all lie in the unit interval from zero to one. On the other hand, the inflow rate into the DHL has a minimum possible value of zero but there is no upper limit to the value it can assume. We stress the fact that these are the mathematical limits as they apply to this model; the values for these parameters and inputs which are physiological are invariably more restricted and rarely extend to their mathematical limits.

Suppose that among the parameters and inputs for the model we choose an arbitrary subset and allow each of the parameters and inputs in this subset to assume or approach one of its extreme values. This maneuver will change some of the Eqs. (1)-(20), and we can study the nature of the solutions of this new set of equations as the remaining parameters and inputs are varied. This is an example of a limit case for the model. Indeed, the limit cases for a model are those in which each parameter or input valuc is assigned or allowed to approach one of its extreme values either one at a time or in various combinations. By studying limit cases, one hopes to derive realistic simplifications of the model and to study the behavior of the full model as these cases are approached.

For the model which we are considering there is a large number of possible limit cases, most of which are of little interest. Those cases in which we are interested and which we will consider in this and the next section involve the volume inflow rates into the DHL, the DVR and the CD, and 
the solute permeabilities in the vasa rectae and their capillary plexuses. We wish to point out again that each of these is an input to the model and can be varied independently of the others. Of course it may well be that not all of the parameters can be varied independently in the renal medulla.

\section{INFLOW INTO THE DVR}

The minimum value which this inflow rate can assume is zero, i.e., $F_{5 v}(0)=0$. In this case, the vasa rectae and their associated capillary plexuses disappear from the model simplifying it considerably. To see this, note that the two terms on the right of Eq. (13) are nonnegative. Hence if $F_{5 v}(0)=0$, either $c_{50}(x)=0$ or $F_{5 v}(x)=0$ or both. We argue on physical grounds that both must be zero. Recall that the equations we have set up are for the steady state. But consider the transients after $F_{5 v}(0)$ is set to zero, assuming the system retains its properties otherwise. The osmotic pressure of the plasma proteins would pull interstitial fluid into the vasa rectae to generate a flow that would flush out the plasma proteins so that in the steady state $c_{50}(x)=c_{60}(x) \equiv 0$. Thus $\Delta \pi_{5}$ tends to zero and so does $\Delta P_{5}$ because there is no pressure gradient at $x=0$ and because of the high permeabilities of urea, salt and water the concentration differences across the walls of the vessels must tend to zero. In effect the contents of the vessels equilibrate with the interstitium. Thus we argue that $J_{5 v}$ goes to zero in the steady state. As a result $F_{5 v}(x)$ must be a constant but since $F_{5 v}(0)=0, F_{5 v}(x)=0$.

The other extreme occurs when $F_{5 v}(0) \rightarrow \infty$. In the limit, because flow is continuous, it is easy to see that $F_{5 v}$ and $F_{6 v}$ become infinite throughout the system whence $F_{5 k}$ and $F_{6 k}$ also become infinite. Moreover, in this case, the fluid entering the DVR is identical in composition with that leaving the AVR, so $c_{5 k}(0)=c_{5 k}(x)=c_{6 k}(x)$ for all $x$. What is the effect of this upon the model? If we approach this limit in such a way that the derivatives in (1) and (2) tend to zero, then from (5) we see that we must have $c_{4 k}(x)$ approach $c_{5 k}(0)$ as a limit assuming of course that the solutes are highly permeable. The physiological implications of this limit case are obvious. If we assume that the vasa rectae are highly permeable to salt and urea, then as $F_{5 v}(0)$ increases, the initial concentrations $c_{5 k}(0)$ will be propagated further and further down the DVR, and the high permeability will promote equilibration between the interstitium and the vasa rectae. The net effect will be to wash out whatever gradients might have existed in the interstitium, almost completely.

\section{INFLOW INTO THE DHL}

As with the DVR, the minimum value which this inflow rate can assume is zero, i.e., $F_{1 v}(0)=0$. In this case, there may be transient movement of fluid and solute into and out from various portions of the DHL and AHL 
while the pump in the AHL depletes the salt concentration in this tubule. In the long run, no inflow into the DHL means that no salt is delivered to the pumps, and no gradient in the interstitium can be developed.

What happens as $F_{1 v}(0) \rightarrow \infty$ ? Starting at low values of $F_{l v}(0)$, as flow into the DHL increases, more and more salt is delivered to the pumps in the AHL. Initially, we expect to see an increase in concentration gradient in the interstitium. However, as $F_{1 v}(0)$ increases two other effects appear that slow the increase in concentration gradient and then decrease it. One is basically a saturation of total pump capacity. The easiest way to see this is to consider what happens as inflow to the AHL increases for constant salt concentration in the fluid entering the AHL. At a high enough flow rate the pumps cannot significantly decrease the concentration in the lumen so all pumps see the same concentration in the lumen and so the maximum total pump capacity is attained for that inflow concentration. The other effect is similar to that described for the vasa rectae. At low flow rates, the luminal fluid is concentrated as it traverses the DHL thus delivering a concentration to the AHL that is higher than that entering the DHL; this is the countercurrent multiplier action. However, the faster the flow rate in the DHL the less effect the interstitial concentration has on the luminal fluid so that in the limit the entering concentration is propagated all the way down the DHL and eventually that is the concentration delivered to the AHL. A very rapid flow in the DHL also tends to wash out the interstitial gradient. We conclude that as $F_{1 c}(0)$ increases, the interstitial gradient first increases, but eventually plateaus and then decreases.

\section{INFLOW TO THE CD}

Both of these extreme cases are of little interest. Indeed, the case when $F_{3},(0)=0$ represents a model with no $\mathrm{CD}$, and the case when $F_{3 v}(0) \rightarrow \infty$ represents infinite urine flow of the same composition as the fluid entering the CD.

\section{SOLUTE PERMEABILITIES IN THE DVR AND AVR}

The limit cases considered here form the basis for the derivation of the central core model. We will defer the discussion of this until the next section.

\section{PHYSIOLOGICAL IMPLICATIONS OF THE INFLOW LIMIT CASES}

What can we learn about medullary function by looking at limit cases? Although the limit cases may not occur in vivo the effects described above in going to the various limits may well be important in normal function. Indeed, the effect of $F_{5 v}(0)$ increasing is usually invoked as one of the mechanisms operative in diuresis. 
What determines the inflow rates into the DHL, the DVR, and the CD, i.e., $F_{1 v}(0), F_{5 v}(0)$, and $F_{3 v}(0)$ ? First, it is obvious that they are not independent in the real situation, so the question then becomes a question of their interdependence and how this fits in with the limit cases. In what follows in this section we argue on physiological and physical grounds; the limit cases have not actually been approached in simulations on a full model containing vasa rectae.

We know that the blood supplying each nephron arrives via the afferent arteriole into Bowman's capsule, and leaves the capsule via the efferent arteriole. The efferent arteriole gives rise to the peritubular capillaries, and the vasa rectae and its capillary plexus. Thus the fluid arriving at Bowman's capsule is divided into two parts, that which becomes the glomerular filtrate and that which leaves in the efferent arteriole.

The first control point for the blood supply to the nephron then is the smooth muscle surrounding the afferent arteriole. When these muscles constrict, the total flow into the nephron is decreased over what it was before, and in the extreme would correspond to the case when $F_{1 v}(0) \rightarrow 0$ and $F_{5 v}(0) \rightarrow 0$. As we have seen, this would be equivalent to removing this nephron as a functional unit. In this case we can say that this unit contributes little to $F_{3 v}(0)$, but, as there are other factors involved in $F_{3 v}(0)$, we can make no overall conclusion about this flow rate. We can think of this particular situation occurring when there is a redistribution of blood flow within the kidney.

The next control point would be the smooth muscles surrounding the efferent arteriole. Indeed, for any given inflow rate in the afferent arteriole and blood composition, the distribution between GFR and flow rate in the efferent arteriole can be controlled by constricting or relaxing these muscles. However, these flow rates are not the flow rates for the fluids entering the DHL and DVR because of the fact that there is reabsorption of water and solutes by the peritubular capillaries along the proximal convoluted tubule. Thus $F_{10}(0)$ is determined by the GFR along with this reabsorption and $F_{5 v}(0)$ is determined by the initial flow in the efferent arteriole along with this reabsorption where we must also take into account the possibility that not all of the capillaries lead into the DVR.

With these facts in mind, let us consider the inflow into the DHL, DVR, and $\mathrm{CD}$ for a given flow rate and blood composition in the afferent arteriole. As $F_{1 v}(0) \rightarrow 0$ we must have $F_{5 v}(0)$ increasing although we cannot say by how much. The contribution of this nephron to flow in the CD would become negligible. A situation such as this could arise in the event that the nephron was damaged. In this case, the effect of $F_{s_{v}}(0)$ would be to decrease the medullary gradient, and we would expect in the extreme an isotonic urine. It is also possible to conceive of the situation in which inflow 
to the DHL becomes small with a concomitant rise in $F_{5 v}(0)$ as the transient behavior of the kidney in passing to a more diuretic state.

On the other hand, as the inflow into the DHL becomes large we would expect a drop in the inflow into the DVR. The initial result would be an increased delivery of salt to the pumps in the AHL. As $F_{5 v}(0)$ decreases, the effect that the vasa rectae has on the concentration gradient in the medulla is decreased, the establishment of the gradient depending primarily on the action of the loops of Henle. Thus again we would expect to see an optimal flow rate for $F_{1 c}(0)$ where the maximal gradient is established followed by a decrease in the gradient.

Finally, the flow into the $\mathrm{CD}$ is partly coupled to that leaving the $\mathrm{AHL}$ so $F_{3 v}(0)$ cannot be varied entirely independently of $F_{1 v}(0)$. For species that have only long Henle loops all of which go into the medulla, $F_{3 v}(0)$ must be determined almost entirely hy $F_{2 v}(0)$ and the subsequent action of the distal tubules on this fluid. However, for many species only a portion of the Henle loops are in the medulla; most of the cortical nephrons have short Henle loops that just get into the outer medulla. For such kidneys $F_{3 v}(0)$ must be determined more by what goes on in the cortical nephrons than by the outflow from the AHL of the juxtamedullary nephrons.

\section{THE CENTRAL CORE MODEL}

In the previous section we saw that in the limit case when $F_{s_{v}}(0)=0$ the vasa rectae and their associated capillary plexuses dropped out of the model. In this section we will consider another limit case, specifically that in which these vessels are infinitely permeable to salt, urea, and other small solutes, and show that it leads to the same conclusion. Stephenson [12] was the first to consider the consequences of such an assumption, and at almost the same time, Kokko and Rector [6] pointed out that this assumption greatly simplified their calculations for mass balance in the inner medulla.

The assumption that Stephenson made was that the reflection coefficients in the vasa rectae and their capillaries for $\mathrm{NaCl}$, urea, and other small solutes were close to zero, i.e., that these solutes were highly permeable. This meant that these tubules could be merged functionally with the interstitium into a single fluid-filled space called the central core. Thus, this leaves the machinery of the concentrating mechanism intact, implicitly retains the functional effect of the vasa rectae in this limit case but greatly simplifies the model.

\section{THE CENTRAL CORE ASSUMPTION}

With the above information in mind, we will sketch the derivation of the central core model. 
Let us write

$$
F(x)=F_{4 v}(x)+F_{5 v}(x)+F_{6 v}(x)
$$

for the combined volume flow rates at level $x$ in the interstitium and vasa rectae. Then, from (7) we obtain upon differentiating

$$
\frac{d F}{d x}=-\sum_{j=1}^{3} \frac{d F_{j v}}{d x}
$$

Differentiating (8) and rearranging terms, we have

$$
\frac{d\left(F_{4 k} c_{4 k}+F_{5 k} c_{5 k}+F_{6 k} c_{6 k}\right)}{d x}=-\sum_{j=1}^{3} \frac{d\left(F_{j v} c_{j k}\right)}{d x}
$$

If the vasa rectae are highly permeable to the solutes in both limbs and in the capillary beds so that $\sigma_{5 k}, \sigma_{6 k}$, and $\sigma_{c k}$ are approximately zero, then we may assume $c_{4 k}=c_{5 k}=c_{6 k}=c_{c k}$, and Eq. (22) may be simplified

$$
\frac{d\left(F c_{4 k}\right)}{d x}=-\sum_{j=1}^{3} \frac{d\left(F_{j 0} c_{j k}\right)}{d x}
$$

This equation tells us that if this assumption is true, then the details of the vasa rectae and their capillary beds may be ignored as far as the concentrating process is concerned, and they can be lumped with the interstitium into an enlarged functional unit. Note that in reaching this conclusion, we have assumed that the loops of Henle and the collecting ducts interact with the vasa rectae only via the interstitium.

Thus the complicated model shown in Fig. 1 reduces to the simpler one shown in Fig. 3. The central core, i.e., the interstitium and the vasa rectae, is labeled with the subscript 4 . This makes our notation the same as that used by Stephenson $[12,17]$ and should facilitate comparison of his work and ours.

THE EQUATIONS OF THE CENTRAL CORE

The equations for the central core model may be obtained directly from (1) and (2) for the loop of Henle and the collecting duct, and Eqs. (21) and 


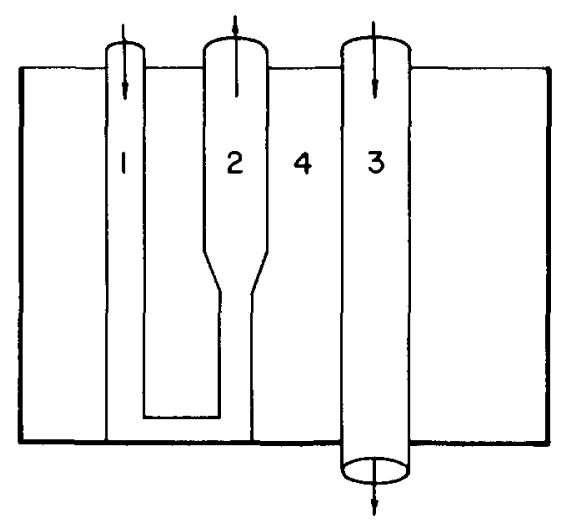

FIG. 3. Schematic diagram of central core model.

(23) for the interstitium. They are:

$$
\begin{aligned}
\frac{d F_{i v}}{d x} & =-S_{i} J_{i v}, \\
J_{i v} & =L_{p} R T \sum_{k} \sigma_{i k}\left(c_{4 k}-c_{i k}\right), \\
\frac{d F_{i k}}{d x} & =-S_{i} J_{i k}, \\
J_{i k} & =\left(1-\sigma_{i k}\right) \frac{c_{4 k}+c_{i k}}{2} J_{i v}-\omega_{i k} R T\left(c_{4 k}-c_{i k}\right)+T_{i k} .
\end{aligned}
$$

Notice that this gives us 12 equations. The solution of these equations gives us $F_{i e}(x)$ and $F_{i k}(x)$. From (3), ignoring the axial diffusion term, we may solve for $c_{i k}(x)$, i.e.,

$$
c_{i k}(x)=\frac{F_{i k}(x)}{F_{i v}(x)} .
$$

BOUNDARY VALUES FOR THE CENTRAL CORE MODEL

There are 10 boundary values listed in Table 2 which apply to the central core model. Since we have 12 equations we need two more. We will derive these now.

From (28), when $x \neq L$, we have $c_{4 k}(x) F_{4 v}(x)=F_{4 k}(x)$. One of the boundary conditions imposed on our model is $F_{4 v}(L)=0$. Assuming that $c_{4 k}(L)$ is finite, it follows because of the continuity of $c_{4 k}(x)$ that $F_{4 k}(L)=0$. Thus (28) is not defined when $x=L$. At this point, however, we may invoke 
l'Hopital's rule. If $d F_{4 v} / d x$ does not vanish when $x=L$, l'Hopital's rule states that

$$
c_{4 k}(L)=\lim _{x \rightarrow L} \frac{d F_{4 k} / d x}{d F_{4 v} / d x}
$$

Substituting (24) and (26) into this expression gives

$$
c_{4 k}(L)=\lim _{x \rightarrow L} \frac{\sum_{j=1}^{3} S_{j} J_{j k}}{\sum_{j=1}^{3} S_{j} J_{j v}} .
$$

This provides two nonlinear relations between $c_{41}$ and $c_{42}$ and the other concentrations at the lower boundary $x=L$. In any numerical solution of (24), (25), (21), and (23) these can be used as added constraints thus giving a full set of 12 boundary conditions.

\section{THE SIGNIFICANCE OF THE CENTRAL CORE MODEL}

We have just seen that the central core assumption, that is, the limit case in which the reflection coefficients for salt and urea in the vasa rectae and their capillary meshwork are close to zero which means that $c_{4 k}=c_{5 k}=c_{6 k}=$ $c_{c k}$ results in the disappearance of the vasa rectae from the model. This implies that the details of the action of the vasa rectae have no influence on the rest of the model. Thus, within the range of blood flows for which this assumption is a good approximation, changing the blood flow to the medulla cannot affect the gradient except possibly in an indirect fashion through an effect on the GFR of the juxtamedullary glomeruli and a consequent change in inflow into the DHL. It is clear that there must be situations in which this is a fairly good approximation; the problem is that we do not know whether these situations overlap the physiologically realizable states of the medulla. Nonetheless, as a model of a concentrating engine, it should provide some insight into the operation of the full model.

\section{PARAMETERS AND INPUT VALUES FOR THE CENTRAL CORE MODEL}

The parameters and input values required for the central core model are of the following types: the geometric parameters, the thermodynamic parameters of the tubules, those which characterize the action of the salt pumps, and the composition and flow rates of the fluid entering the tubules. Recall that the notation for each is listed in Table 1. 
The geometric parameters which have been directly measured and $r \because-$ ported in the literature are summarized in Table 3, arranged in order of increasing maximum urine concentration attainable. The reference for each entry is given in square brackets.

Of course what is required for the model is the surface area per unit length for the various tubules. For the ascending and descending limbs of Henle, these have been computed from a knowledge of the luminal diameters, and are summarized in Table 4. Notice that we have sufficient information to calculate or make reasonable estimates only for the rabbit, rat, hamster and man.

The major problem was obtaining estimates for the collecting ducts. The numbers for the collecting ducts in man were calculated from $C:$ ver's data [27]. According to Oliver, there are about 350 collecting trees in the human kidney, each tree being formed by 8 or 9 successive dichotomous branchings of a papillary duct, and resulting in an estimated 90,000 to 180,000 collecting ducts at or near the corticomedullary border. Since the mean number of ducts decreases as one moves from the corticomedullary border into the medulla, we have used the smaller number, 90,000. From the data in Table 3, we estimated an average diameter for the collecting duct as double that of the limbs of Henle. Using these figures, we obtain a surface area per unit length in the human kidney which is just about the same as that estimated for the loops of Henle. If the ratio of the collecting ducts to long ioops of Henle remains the same in the other species and if the average diameters of the collecting ducts is double that of the loops of Henle the surface area per unit length of the collecting duct is approximately the same as for the loops of Henle. These figures are also summarized in Table 4 with the figures for the nonhuman cases being put in parenthesis to stress their hypothetical nature.

\section{THERMODYNAMIC PARAMETERS}

Almost all of the measurements of the reflection coefficients, permeability coefficients, and filtration coefficients have been obtained for the rat and rabbit. As we mentioned in the introduction, the data on the rabbit tubules come from experiments on isolated tubules whereas the rat data come from estimates based upon micropuncture studies. Table 5 presents our summary of the data available in the literature. It is interesting to note that in many cases there are sizable differences in the permeability properties of the same tubular segment between the rat and the rabbit.

\section{TRANSPORT PARAMETERS}

The equation for the pump, Eq. (6), has three independent parameters. This form has the advantage that, as for the Michaelis-Menten equation, the 


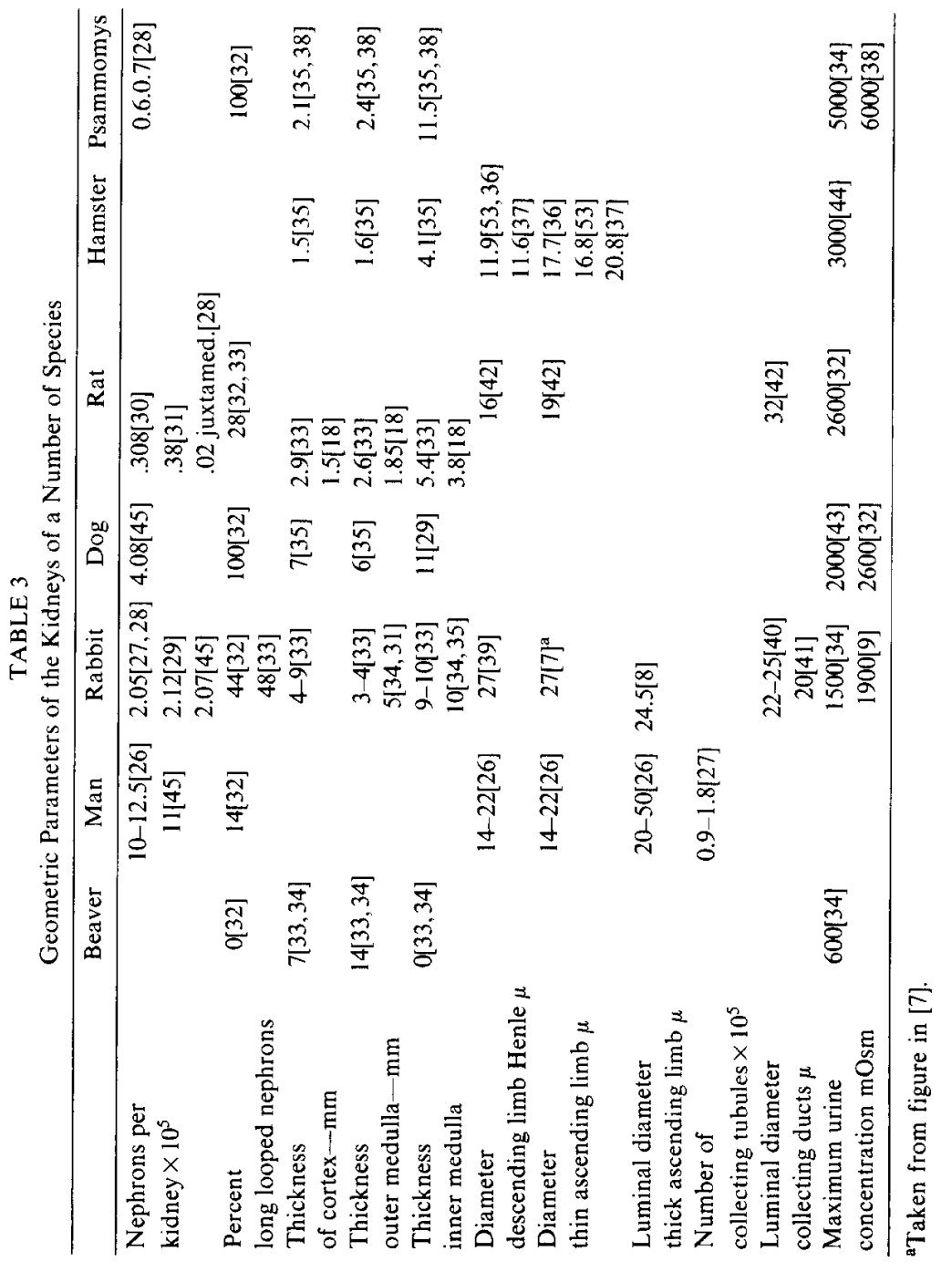


TABLE 4

Lengths and Surface Areas of Tubules

\begin{tabular}{ccccc}
\hline & Man & Rabbit & Dog & Rat \\
\hline$L_{1}(\mathrm{~cm})$ & $1.0 ?$ & 0.5 & 0.6 & 0.25 \\
$L_{2}(\mathrm{~cm})$ & 1.0 & 1.0 & 1.1 & 0.50 \\
$\begin{array}{l}\text { Diameter } \\
\text { Thin and thick Henle }(\mu)\end{array}$ & 22 & 27 & 22 & 18 \\
$\begin{array}{l}S-\mathrm{cm}^{2} / \mathrm{cm} \\
\text { Descending and thin } \\
\text { and thick ascending }\end{array}$ & 1200 & 800 & 2800 & 50 \\
$\begin{array}{l}S-\mathrm{cm}^{2} / \mathrm{cm} \\
\text { Collecting ducts }\end{array}$ & 1200 & $(800)$ & $(2800)$ & $(50)$ \\
\hline
\end{tabular}

net flux is saturable in the cis concentration; it has the added advantage of being inhibited by an increase in the trans concentration. As pointed out by Jacquez et al. [21], Eq. (6) describes the experimental data on transport across renal tubules fairly well, and values for the parameters have been given for the proximal and distal tubules of the rat in [21]. We defer presenting the values which we will use in our simulations until the next paper.

\section{TUBULAR FLUID COMPOSITION AND FLOW RATES}

For input into the model we must have the flow rate and composition of the fluids entering the DHL and CD at the corticomedullary border. Since the model predicts the flow rate and composition of the fluids leaving the top of the AHL and the bottom of the $\mathrm{CD}$, we must also have the experimentally determined values for these to serve as the basis for comparisorl.

The urine flow rate and composition has been measured in several species. Thus it is an easy matter to compare the predicted values with the observed values. Moreover, micropuncture studies have given us values for the fluid composition in various tubular segments, but unfortunately these are available only for certain species of rodents. The remaining values that are required must be estimated from our knowledge of GFR and tubular reabsorption and secretion.

We will defer until the next paper our table of input concentrations and flow rates, and summarize here only our values for urine concentration and flow rates. Table 6 lists the excretion rates for rat, rabbit, dog and man which we have taken from one of the biological handbooks [58], and Table 7 gives urine concentrations under conditions of hydropenia and water diuresis. 
TABLE 5

Thermodynamic Parameters

\begin{tabular}{|c|c|c|}
\hline Descending limb of Henle & Rabbit & Rat \\
\hline \multicolumn{3}{|l|}{$\left(\mathrm{cm} \cdot \min ^{-1} \times 10^{-3}\right)$} \\
\hline$\sigma_{\mathrm{Na}}$ & $0.96[39]$ & $0.36[6]$ \\
\hline$k_{\text {urea }}$ & $0.90[46]$ & No ADH: $7.8[42]$ \\
\hline$\left(\mathrm{cm} \cdot \min ^{-1} \times 10^{-3}\right)$ & & ADH: 12.0 \\
\hline$\sigma_{\text {urea }}$ & $0.95[46]$ & $0.44[6]$ \\
\hline $\mathrm{RTL}_{p} T=37^{\circ}$ & $0.247[46]$ & $0.06599[42]$ \\
\hline$\left(\frac{\mathrm{cm}^{3}}{\mathrm{~cm}^{2} \cdot \min } \cdot \frac{\mathrm{cm}^{3}}{\mathrm{mmole}}\right)$ & & \\
\hline \multicolumn{3}{|l|}{ Ascending limb of Henle } \\
\hline$k_{\mathrm{Na}}$ & $\begin{array}{l}\text { THIN: } 15.3[7] \\
\text { THICK: } 3.76[8]\end{array}$ & \\
\hline${ }^{\sigma_{\mathrm{Na}}}$ & $\begin{array}{l}\text { Thin: } 70.2[7] \\
\text { THICK: } 0.636[8]\end{array}$ & THIN: $1[6]$ \\
\hline$\sigma_{\mathrm{Cl}}$ & & THIN: $1[6]$ \\
\hline \multirow{2}{*}{$\begin{array}{l}{ }^{0} \mathrm{Cl} \\
k_{\text {urea }}\end{array}$} & THIN: 4.02[7] & No ADH: $8.4[42]$ \\
\hline & THICK: $0.516[47]$ & ADH: $9.6[42]$ \\
\hline$\sigma_{\text {urea }}$ & & THIN: $0.3[6]$ \\
\hline \multirow[t]{2}{*}{$\mathrm{RTL}_{p}$} & THIN: $0.00142[7]$ & $0.0050[42]$ \\
\hline & $\begin{aligned} \text { THICK: } & 0.000183[8] \\
& 0.00000764[48]\end{aligned}$ & \\
\hline \multicolumn{3}{|l|}{ Collecting duct } \\
\hline$k_{\mathrm{Na}}$ & No ADH: $0.036[49]$ & $\begin{array}{l}7.56 \text { (corrected for } \\
\text { active transport }[50])\end{array}$ \\
\hline$\sigma_{\mathrm{Na}}$ & $1[50,51]$ & $1[59]$ \\
\hline$\sigma_{\mathrm{Cl}}$ & $1[50,51]$ & $1[59]$ \\
\hline \multirow{8}{*}{$\begin{array}{l}k_{\text {urea }} \\
k_{\text {ul }}\end{array}$} & No ADH: $0: 18[50]$ & No ADH: $12.0[11]$ \\
\hline & $0.63[41]$ & $8.28[55]$ \\
\hline & $0.096[52]$ & \\
\hline & $0.055[16]$ & \\
\hline & $\mathrm{ADH}: 0.12[50]$ & $\mathrm{ADH}: 18.0[11]$ \\
\hline & $0.732[41]$ & $12.12[55]$ \\
\hline & $0.090[52]$ & \\
\hline & $0.058[11]$ & \\
\hline$\sigma_{\text {urea }}$ & $1[51,52]$ & $0.4[17]$ \\
\hline $\mathrm{RTL}_{p}$ & $0.000652[40]$ & $0.00478[42]$ \\
\hline \multirow[t]{4}{*}{ No ADH } & $0.00785[41]$ & $0.00467[55]$ \\
\hline & $0.00278[54]$ & $0.00580[55]$ \\
\hline & & Antidiuresis: $0.00488[56]$ \\
\hline & & $0.00539[57]$ \\
\hline $\mathrm{RTL}_{p}$ & $0.0202[40]$ & $0.0341[42]$ \\
\hline \multirow[t]{2}{*}{ ADH present } & $0.0264[41]$ & $0.0239[55]$ \\
\hline & $0.0135[54]$ & $0.0228[55]$ \\
\hline
\end{tabular}


TABLE 6

Excretion Rates

\begin{tabular}{lccccc}
\hline & Units & Rat & Rabbit & Dog & Man \\
\hline Volume & $\mathrm{ml} / \mathrm{kgm-day}$ & $15-30$ & $50-75$ & $20-100$ & $9-29$ \\
Sodium & $\mathrm{mEq} / \mathrm{kgm}$-day & $4.5(1.7-7.3)$ & & $1.9(0.04-13)$ & $2.6(1.1-4.1)$ \\
Chloride & $\mathrm{mEq} / \mathrm{kgm}$-day & $3.4(0.9-8.2)$ & $0.5(0.1-1.4)$ & $2.0(0-10.3)$ & $2.8(1.13-5.0)$ \\
Urea & $\mathrm{mmoles} / \mathrm{kgm}$-day & $16.7-26.7$ & $20-25$ & $5.0-8.3$ & $3.3-8.3$ \\
Creatinine & mmoles $/ \mathrm{kgm-day}$ & $0.21-0.35$ & $0.18-0.44$ & $0.27-0.71$ & $0.2(0.13-0.27)$ \\
\hline
\end{tabular}

TABLE 7

Concentration in Urine (mEq/L or mmoles/L)

\begin{tabular}{lcccc}
\hline & Rat & Rabbit & Dog & Man \\
\hline Sodium & 90 & 60 & $74(2-189)$ & $114(35-167)$ \\
Chloride & 96 & $41(3.4-94)$ & $76(0-289)$ & $110(49-210)$ \\
Urea & 111 & & & \\
\hline
\end{tabular}

\section{SUMMARY AND CONCLUSIONS}

In this paper we have developed two models for concentrating engines which can be viewed as first approximations to the concentrating mechanism in the medulla. Although from the point of view of mimicking medullary function the full model is probably a better approximation, we found that it presented insurmountable theoretical and experimental difficulties. Hence we were led to the central core model.

How do these models fit into the overall picture of the modeling of medullary function? The model of Hargitay and Kuhn assumed that the movement of water across the walls of the loops of Henle was due to pressure filtration although they acknowledged that the known pressure differences in the kidney were too small to account for the total force required [2]. Kuhn and Ramel [4] changed this to the active extrusion of sodium as the driving force of the system and at the same time omitted the vasa rectae and the flow of water across the tubular walls. These omissions along with the omission of nontransported solutes such as urea makes such a model unrealistic. Pinter and Shohet [59] were the first to try to include the vasa rectae in such a model but they did not allow the water to move across the walls of the tubules. Stephenson [60] showed that such a model could not concentrate solute and Kelman et al. [61] showed that the concentration profile was nonmonotonic.

Jacquez et al. [21] formulated a model of both the medulla and cortex that included the movement of a transported solute, a nontransported 
solute, and water. The model of the medulla included the vasa rectae, the loops of Henle, and the collecting ducts; the geometry was essentially the same as Fig. 1. The equations used to describe the model consisted of equations for the conservation of water, of transported solute, and of nontransported solute, but the equations of motion of volume flow down the tubules were omitted. No solutions of the equations were presented. Marumo et al. [62] published the same type of model and included the equations of motion for flow in the tubules but used a sodium pump that was linear in the sodium concentration in the ascending limb of Henle. They publish graphs that show a concentration effect. Furukawa et al. [63] also worked on the same type of model except for the nature of the transport function and the fact that they tapered the medulla towards the papillae.

I ieberstein [64] returned to the original model of Hargitay and Kuhn in that his driving force was pressure filtration; active transport of solute as the driving force was specifically excluded. In view of the evidence for active transport, this model would appear to be incorrect.

Koushanpour et al. [65] in their simulation of the medulla used only the conservation equations. They also assumed known linear gradients in the transported and nontransported solutes. These assumptions simplify the mathematics considerably since they uncouple the equations for solute and solvent movement in each tubule from those in the other tubules, but this approach is really an evasion of the basic problem which is to see if and how such a model develops a concentration gradient in the medulla.

Kokko and Rector [6], as we have pointed out previously, presented a model for the countercurrent multiplication system in which there was no active transport in the inner medulla. This model focuses on the action of the loops of Henle and the collecting ducts in the medulla. Some of the mathematical analysis of this model was done by Stewart et al. [13].

Palatt and Saidel [66] tried to incorporate some of the anatomical interrelations described by Kriz [18] into a model in which the descending vasa rectae exchange solutes and water with the ascending loop of Henle, and the ascending vasa rectae exchange with the descending loop of Henle; the capillary plexus exchanges with the ascending loop of Henle and the collecting ducts. The model does not include equations of motion for the vasa rectae or the capillary bed, and the equations for water movement across the tubular walls do not include the filtration terms.

As we have stated, the central core model was originally introduced by Stephenson [12]. It will serve as the basis for our simulations which we present in the next paper.

The authors thank Dr. James A. Schafer and Dr. John Stephenson for their critical review of this and the succeeding paper. 


\section{REFERENCES}

1 W. Kuhn, and K. Ryffel, Herstellung konzentrierter Losungen aus verdunnten durch blosse Membran-wirkung, Ein Modellversuch zur Function der Niere, Ztschr. Physiol. Chem 276, 145-178 (1942).

2 B. Hargitay, and W. Kuhn, Das Multiplikationsprinzip als Grundlage der Harnkonzentration in der Niere, Z. Elektrochem. 55, 539-558 (1951).

3 H. Wirz, B. Hargitay and W. Kuhn, Lokalisation des Konzentrierungs prozesses in der Niere durch direkte Kryoskopie, Helv. Physiol. et Pharmacol. Acta 9, 196-207 (1951).

4 W. Kuhn, and A. Ramel, Aktiver Salztransport als moglicher (und wahrscheinlicher). Einzeleffekt bei der Harnkonzentrierung in der Niere, Helt. Chim. Acta 42, 628-660 (1959).

5 R. L. Jamison, Countercurrent systems, MTP intern. rev. science, Kidney and Urinary Tract Physiol., K. Thurau, ed., Butterworths, London, 1974, Vol. 6, pp. 199-245.

6 J. P. Kokko, and F. C. Rector, Jr., Countercurrent multiplication system without active transport in inner medulla, Kidney Internat. 2, 214-223 (1972).

7 M. Imai, and J. P. Kokko, Sodium chloride, urea, and water transport in the thin ascending limb of Henle, J. Clin. Invest. 53, 393-407 (1974).

8 A. S. Rocha, and J. P. Kokko, Sodium chloride and water transport in the medullary thick ascending limb of Henle: Evidence for active chloride transport, J. Clin. Invest. 52, 612-613 (1974).

9 D. J. Marsh, Solute and water flow in thin limb of Henle's loop in the hamster kidney, Am. J. Physiol. 218, 824-831 (1970).

10 C. W. Gottschalk, Micropuncture studies of tubular function in the mammalian kidney, Physiologisi 4, 35-55 (1961).

1 I M. B. Burg, and J. Orloff, Perfusion of isolated renal tubules, Renal physiology, Handbook of Physiology, J. Orloff and R. W. Berliner, eds., Am. Physiol. Soc, Washington, DC, 1973, Chapt. 7, Sect. 8.

$12 \mathrm{~J}$. L. Stephenson, Concentration of urine in a central core model of the renal counterflow system, Kidney Internat. 2, 85-94 (1972).

13 J. Stewart, M. E. Luggen and H. Valtin, A computer model of the renal countercurrent system, Kidney Internat. 2, 253-263 (1972).

14 J. Stewart, and H. Valtin, Computer simulation of osmotic gradient without active transport in renal inner medulla, Kidney Internat. 2, 264-270 (1972).

15 J. L. Stephenson, Concentrating engines and the kidney-I. Central core model of the renal medulla, Biophys. J. 13, 512-545 (1973).

16 J. L. Stephenson, Concentrating engines and the kidney-II. Multisolute central core systems, Biophys. J. 13, 546-567 (1973).

17 J. L. Stephenson, R. P. Tewarson and R. Mejia, Quantitative analysis of mass and energy balance in non-ideal models of the renal counterflow system, Proc. Nat. Acad. Sci. USA 71, 1618 (1974).

18 W. Kriz, Der architektonische and funktionelle Aufbau der Rattenniere, $Z$. Zellforsch. Mikroskip. Anat. 82, 495-535 (1967).

19 L. W. Welling, and D. J. Welling, Pressure-flow-diameter relationships in isolated perfused thin limb of Henle, Am. J. Physiol. 229, 1-7 (1975).

20 A. Katchalsky, and P. F. Curran, Nonequilibrium Thermodynamics in Biophysics, Harvard Univ. Press, Cambridge, Mass., 1965.

21 J. A. Jacquez, B. Carnahan and P. Abbrecht, A model of the renal cortex and medulla, Math. Biosci. 1, 227-261 (1967). 
22 B. Schmidt-Nielsen, Urea excretion in mammals, Phys. Rev. 38, 139-168 (1958).

23 A. S. Berman, Laminar flow in channels with porous walls, J. Appl. Physics 24, 12321235 (1953).

24 S. W. Yuan, and A. B. Finkelstein, Laminar pipe flow with injection and suction through a porous wall, Trans. Am. Soc. Mech. Eng. 78, 719-724 (1956).

25 R. I. Macey, Pressure flow patterns in a cylinder with reabsorbing walls, Bull. Math. Biophysics 25, 1-9 (1963).

26 R. G. Pitts, Physiology of the Kidney and Body Fluids, Year Book Medical Publishers, Chicago, 1974.

27 J. Oliver, Nephrons and Kidneys, Harper and Row, New York, 1968.

28 E. M. Renkin, and J. P. Gilmore, Glomerular filtration, Renal physiology, Handbook of Physiology, J. Orloff and R. W. Berliner, eds., Am. Physiol. Soc., Washington, DC, 1973. Chapt. 9, Sect. 8.

29 B. J. Nelson, The number of glomeruli in the kidney of the adult rabbit, Anat. Rec. 23, 355-361 (1922).

30 E. E. Windhager. Micropuncture Techniques and Nephron Function. AppletonCentury-Crofts, New York, 1968.

31 L. J. Barrat, J. D. Wallin, F. C. Rector, Jr., and D. W. Seldin, Influence of volume expansion on single-nephron filtration rate and plasma flow in the rat, Am. J. Physiol. 224, 643-650 (1973).

32 B. Schmidt-Nielsen, and R. O'Dell, Structure and concentrating mechanism in the mammalian kidney, Am. J. Physiol. 200, $1119-1124$ (1961).

33 1. Sperber, Studies on the mammalian kidney, Zool. Bidrag. fran Uppsala 22, 249 (1944).

34 R. O'Dell, and B. Schmidt-Nielsen, Concentrating ability and kidney structure, Fed. Pror. 19, 366 (1960).

35 S. E. Dicker, Mechanisms of Urine Concentration and Dilution in Mammals, Williams and Wilkins Co., Baltimore, 1970.

36 D. J. Marsh, and S. Solomon, Analysis of electrolyte movement in thin Henle's loop of hamster papilla, Am. J. Physiol. 208, $1119-1128$ (1965).

37 K. Thurau, and G. Henne, Dynamik des Harnstromes in den Henleschen Schleife, Arch. Ges. Physiol. 278, 45-46 (1963).

38 B. Schmidt-Nielsen, and L. Rabinowitz, Methylurea and acetamide: Active reabsorption by elasmobranch renal tubules, Science 146, 1587-1588 (1964).

39 J. P. Kokko, Sodium chloride and water transport in the descending limb of Henle, $J$. Clin. Invest. 49, 1838-1846 (1970).

40 J. Schafer, and T. E. Andreoli, Cellular constraints to diffusion, The effect of antidiuretic hormone on water flows in isolated mammalian tubules, J. Clin. Invest. 51, 1264-1278 (1972).

41 J. J. Grantham, and M. B. Burg, Effect of vasopressin and cyclic AMP on permeability of isolated collecting tubules, Am. J. Physiol. 211, 255-259 (1966).

42 T. Morgan, and R. W. Berliner, Permeability of the loop of Henle, vasa rectae, and collecting duct to water, urea, and sodium, Am. J. Physiol, 215, 108-115 (1968).

43 S. E. Bradley, J. H. Laragh, H. O. Wheeler, M. MacDowell and J. Oliver, Correlation of structure and function in the handling of glucose by the nephrons of the canine kidney, I. Clin. Incest. 40, 1113-1131 (1961).

44 F. Morel, and M. Guinnebault, Les mechanismes de concentration et de dilution de l'urine, J. Physiol. (Paris) 53, 75-130 (1961).

45 H. W. Smith, The Kidney: Structure and Function in Health and Disease, Oxford University Press, New York, 1951. 
46 J. P. Kokko, Urea transport in the proximal tubule and the descending limb of Henle, J. Clin. Invest. 51, 1999-2008 (1972).

47 J. P. Kokko, Membrane characteristics governing salt and water transport in the loop of Henle, Fed. Proc. 33, 25-30 (1974).

48 M. B. Burg, and N. Green, Function of the thick ascending limb of Henle's loop, Am. J. Physiol. 224, 659-668 (1973).

49 G. Frindt, and M. B. Burg. Effect of vasopressin on sodium transport in renal cortical collecting tubules, Kidney Internat. 1, 224-231 (1972).

50 J. A. Schafer, and T. E. Andreoli, The effect of antidiuretic hormone on solute flows in mammalian collecting tubules, J. Clin. Invest. 51, 1279-1286 (1972).

51 J. A. Schafer, and T. E. Andreoli, Vasopressin-dependent reflection coefficients in isolated collecting tubules, Physiologist 13, 302 (1970).

52 M. B. Burg, Urea and the Kidney, B. Schnidt-Nielsen and D. W. S. KerI, eds., Excerpta Med. Found., Amsterdam, 1970.

53 M. Steinhousen, In vivo-Beobachtungen und der Nierenpapille von Goldhamstern nach intravenoser Lissamingrun-Injektion, Arch. Ges. Physiol. 279, 195-213 (1964).

$54 \mathrm{~J}$. J. Grantham, and J. Orloff, Effect of protaglandin $E_{1}$ on the permeability response of the isolated collecting tubule to vasopressin, J. Clin. Invest. 47, 1154-1161 (1968).

55 T. Morgan, F. Sakai and R. W. Berliner, In vitro permeability of medullary collecting ducts to water and urea, Am. J. Physiol. 214, 574-581 (1968).

56 K. J. Ullrich, G. Rumrich and G. Fuchs, Wasser permeabilitat und transtubularer Wasserfluss corticaler Nephronabschnitte bei verschiedenen Diuresezustanden, Arch. Ges. Physiol. 280, 99-119 (1964).

57 H. Stolte, J. P. Brecht, M. Wiederholt and K. Hierholzer, Einfluss von Adrenalek tomie und Glucocorticoiden auf die Wasserepermeabilitat corticaler Nephronabschnitte der Rattenniere, Arch. Ges. Physinl. 299, 99-127 (1968).

58 P. L. Altman and D. S. Dittmer, eds., Blood and Other Body Fluids, Biological Handbook, Fed. Am. Soc. for Exptl. Biology, Washington, DC, 1961.

59 G. G. Pinter and J. L. Shohet, Origin of sodium concentration profile in the renal medulla, Nature 200, 955-958 (1963).

60 J. L. Stephenson, Ability of counterflow systems to concentrate, Nature 206, 1215-1219 (1965).

61 R. B. Kelman, D. J. Marsh and H. C. Howard, Nonmonotonicity of solutions of linear differential equations occurring in the theory of urine formation, SIAM Rev. 8 , 463-478 (1966).

62 F. Marumo, Y. Yoshikawa and S. Koshikawa, A study on the concentration mechanism of the renal medulla by mathematical model, Jap. Circul. J. 31, 1309-1317 (1967).

63 T. Furukawa, S. Takasugi, M. Inoue, H. Inada, F. Kajiya and H. Abe, A digital computer model of the renal medullary countercurrent system-I. Comput. Biomed. Res. 7, 213-229 (1974).

64 H. M. Lieberstein, The significance of viscous flow properties in the theory of operation of a nephron, Math. Biosci. 4, 49-102 (1969).

65 E. Koushanpour, R. R. Tarica and W. F. Stevens, Mathematical simulation of normal nephron function in rat and man, $J$. Theor. Biol. 31, 177-214 (1971).

66 P. J. Palatt, and G. M. Saidel, Countercurrent exchange in the inner renal medulla: Vasa recta-descending limb system, Bull. Math. Biol. 35, 431-447 (1973). 